\title{
TRABAJADORES A HONORARIOS. LA MUNICIPALIDAD COMO TRANSGRESOR DEL ORDEN PÚBLICO LABORAL. ${ }^{1}$
}

\section{FEE WORKERS UNDER CHILEAN SYSTEM MUNICIPALITY AS A TRANSGRESSOR OF LABOUR PUBLIC ORDER}

\author{
FRANCISCO JAVIER NEIRA REYES.* \\ Abogado \\ ALVARO ROJAS MUÑOZ** \\ Abogado
}

\begin{abstract}
RESUMEN: La sobreutilización irregular de la modalidad de contratación honorarios al interior de la administración del Estado es un fenómeno que se ha naturalizado en el cumplimiento de las funciones gubernamentales. Este mecanismo, destinado a tareas accidentales o específicas, ha sido empleado en los distintos niveles de la administración bajo regímenes de subordinación y dependencia, lo que pone en peligro la observancia al Orden Público Laboral y el reconocimiento de derechos laborales mínimos consagrados a favor de todo ciudadano.
\end{abstract}

PALABRAS CLAVE: contrato de honorarios; Municipalidad; orden público laboral; contrato de trabajo

ABSTRACT: The irregular overuse of contract fees at the state administration, is a phenomenon that has become commonly used to fulfill government functions. This mechanism, established in our legal system, only to accidental or specific tasks, is used at various levels of government, under regimes of subordination or dependence, which threatens the observance of the Labour Public Order and the recognition of consecrated labor rights for all citizens.

KEY WORDS: fee workers; Municipality; labour public order; contract of employment

\section{INTRODUCCIÓN}

La problemática de los trabajadores a honorarios se centra principalmente en la existencia al interior de la administración de contratos de prestación de servicios bajo

\footnotetext{
${ }^{1}$ Este artículo desarrolla ideas expuestas en Neira Reyes, Francisco y Rojas Muñoz. Álvaro (2015). Los Trabajadores a Honorarios de la Administración Municipal: Su desregulación como vulneración al Orden Público Laboral. Memoria de grado-Mención Honrosa 2015. (Santiago, Facultad de Derecho, Universidad de Chile.)

* Abogado de la Dirección Nacional del Trabajo. Licenciado en Ciencias Jurídicas y Sociales de la Facultad de Derecho, Universidad de Chile. fjneira@ug.uchile.cl

** Abogado. Licenciado en Ciencias Jurídicas y Sociales de la Facultad de Derecho, Universidad de Chile. alvarorhcp@ug.uchile.cl
}

Este trabajo fue recibido el 31 de mayo de 2016 y aprobado el 30 de junio de 2016. 
subordinación o dependencia, produciéndose una relación laboral en la que, en términos formales, no se ha reconocido normativa tutelar pese a la disparidad de poderes entre el trabajador y la administración local o central.

En este sentido, La Presidenta Michelle Bachelet en el año 2015, anunciaba en su mensaje presidencial una medida tendiente a mejorar las condiciones de empleo para los funcionarios del sector público: "Y una noticia muy relevante: al finalizar el período presidencial, no habrá trabajadores desempeñando funciones permanentes en el Gobierno Central a honorarios. Se propone, en una primera etapa, la implementación de un plan de traspasos de ocho mil 800 trabajadores, que actualmente están contratados a honorarios, a la modalidad de contrata." (Bachelet, 2015: 9)

En dicha oportunidad el anuncio nos merecía cierta preocupación; en primer lugar, se desnaturalizaba la modalidad de la contrata ${ }^{2}$ y, en segundo lugar, no abordaba la realidad de los trabajadores a honorarios de la Administración Municipal, pese a que estos forman parte de la misma problemática que los trabajadores del gobierno central. Esta circunstancia se sumaba al hecho de que estos tampoco fueron incorporados en posteriores instancias de diálogo social ${ }^{3}$, lo que nos motivó a analizar las particularidades de este sector laboral.

Ahora bien, de forma paralela al anuncio, se inició un proceso legislativo ${ }^{4}$ que modificaba el artículo 65, $\mathrm{N}^{\mathrm{0}}$ 2, de la Constitución Política de la República, que consagraba que la creación de nuevos empleos fiscales era materia de iniciativa exclusiva del Presidente de la República. Dicha situación entendíamos representaba una dificultad adicional para las municipalidades $\mathrm{y}$, en razón de ello, una eventual reforma a la Constitución y a la Ley Orgánica de Municipalidades, en la que se entregara la facultad de fijar y modificar plantas a los alcaldes; parecía indirectamente un avance en la solución de la problemática de los trabajadores a honorarios de la Administración Municipal.

Al momento de la presentación de este trabajo, el proyecto de ley que modifica disposiciones aplicables a los funcionarios municipales y entrega nuevas competencias a la Subsecretaría de Desarrollo Regional y Administrativo, se encuentra aprobado por el Congreso y promulgado por la Presidenta Bachelet, sin embargo, según informaciones emanadas desde el gobierno ${ }^{5}$, la iniciativa beneficiaría a 33 mil funcionarios, lo que sumado al hecho de que no se trata de una política destinada directamente a los trabajadores a honorarios - nos merece preocupación debido a la magnitud de la problemática que se expondrá en esta investigación.

Cabe destacar que la normativa pronta a publicarse establece su acento en el traspaso de los funcionarios de la contrata a la planta municipal $\mathrm{y}$, subsidiariamente, en virtud de lo consagrado en sus disposiciones transitorias, se consigna la intención de traspasar trabajadores a honorarios a la contrata, otorgando prioridad a aquellos con cargo al subtítulo 21, ítem 03, del presupuesto municipal, referido fundamentalmente a la

\footnotetext{
${ }^{2}$ En este sentido, el artículo $3^{\circ}$, letra c), de la Ley $\mathrm{n}^{\circ} 18.834$, define el empleo a contrata como aquél de carácter transitorio que se consulta en la dotación de una institución, circunstancia que consideramos ajena a la realidad de la Administración y a las funciones que cumplirían los trabajadores a honorarios.

${ }^{3}$ Véase en Dirección de Presupuestos (2015).

${ }^{4}$ Bachelet (2015)

${ }^{5}$ Subsecretaría del Desarrollo Regional y Administrativo (2016)
} 
modalidad suma alzada, cuyo porcentaje en relación al universo de la contratación a honorarios es marginal y que, según revisaremos, se concentra en la modalidad programas comunitarios.

Adicionalmente, en lo relativo a la operatoria jurídica de la contratación bajo programas comunitarios, la normativa en comento mantiene incólume dicho aspecto, no siendo abordada esta arista de la contratación a honorarios, la que reviste ciertas particularidades necesarias de considerar, según expondremos.

No obstante lo expuesto, verificar el real efecto y alcance de la normativa solo será posible en virtud de los antecedentes que surjan en el periodo próximo a su implementación, sin embargo, mientras continúen desempeñándose trabajadores a honorarios en régimen de subordinación y dependencia, reafirmamos la posición del reconocimiento de un derecho tutelar por vía de aplicar el Código del Trabajo, no solo por razones de texto, sino que además por la observancia al Orden Público Laboral.

\section{CUESTIONES GENERALES.}

Los trabajadores a honorarios que prestan servicios al interior de la Administración Municipal, al igual que los funcionarios públicos ${ }^{6}$ del nivel central, conforme a la normativa vigente y bajo una óptica formalista, se encuentran en una relación jurídica simétrica y sin reconocimiento de una normativa tutelar, bastándose la normativa que se han otorgado las partes en el contrato a honorarios y, supletoriamente, la establecida en el Código Civil.

Respecto del contrato a honorarios podemos señalar que es un contrato atípico que ha sido homologado por la doctrina al contrato de arrendamiento de servicios, regulado en el artículo 1915 Código Civil, más específicamente en el párrafo IX, Título XXVI, del libro IV, acerca "del arrendamiento de servicios inmateriales", en donde se diferencian aquellos servicios aislados en los que predomina la inteligencia sobre la mano de obra (artículo 2006) y los servicios que consisten en una larga serie de actos (artículo 2007). Adicionalmente, se reconoce un tercer tipo correspondiente a prestación de servicios profesionales (artículo 2118 en relación con el artículo 2012).

Ahora bien, independiente de la posible homologación del contrato a honorarios, este último tiene una serie de características propias; es un acto jurídico bilateral oneroso, donde el objeto del contrato será la prestación de servicios en favor de otro y la entrega, por regla general, de una suma de dinero por dichos servicios, pudiendo identificarse como elementos esenciales de este contrato la igualdad contractual; la prestación de servicios; y el pago de honorarios (Muñoz y Umaña, 2012: 16).

En este sentido, destacamos como presupuesto esencial de esta contratación la igualdad formal y material de los contratantes, que representa una manifestación de la autonomía de

\footnotetext{
${ }^{6}$ En el presente trabajo conceptos como funcionario público, funcionario municipal, trabajador municipal o empleado municipal, serán empleados como sinónimos. Cuando se otorgue un sentido distinto se realizará la advertencia correspondiente
} 
la voluntad, piedra angular del derecho privado. En virtud de esta consideración, afirmamos que en este contrato las partes tienen amplias libertades para obligarse dentro de los límites que le imponen el orden público, las buenas costumbres o la ley.

Por contrapartida, en el caso de una relación laboral, la igualdad material no es verificable $\mathrm{y}$, en consecuencia, ante la existencia de un vínculo de subordinación o dependencia, se genera el imperativo de limitar la libertad de configuración contractual y se justifica la necesidad de protección jurídica, consagrando derechos mínimos por la disparidad en el poder de negociación de las partes. Así las cosas, el elemento esencial para determinar si estamos ante un contrato a honorarios o una relación de naturaleza laboral, será la concurrencia de la igualdad contractual o la subordinación o dependencia, respectivamente.

En términos normativos no existe definición específica sobre qué significa subordinación, en este sentido, la Real Academia Española la ha definido como "sujeción a la orden, mando o dominio de alguien" ". La jurisprudencia administrativa, emanada de la Dirección del Trabajo, adicionalmente ha establecido una serie de manifestaciones de la subordinación en las relaciones laborales tales como: continuidad o permanencia de los servicios prestados, obligación de asistencia del trabajador, supervigilancia en el desempeño de las funciones, la subordinación a instrucciones, etcétera. Agregando que, en estos casos, estaremos en presencia de una relación laboral pese la denominación que hayan realizado las partes. ${ }^{8}$

Es necesario advertir que al interior de la Administración Municipal existen ciertas particularidades respecto de la relación laboral, lo que también afecta al el régimen de subordinación o dependencia en consideración a la calidad de empleado público ${ }^{9}$ que detentan estos trabajadores. En este sentido, el Estado - Municipalidad - será uno de los sujetos concurrentes u obligados; actuando como empleador $\mathrm{y}$, por contraparte, el trabajador que denominaremos funcionario o empleado público, será un dependiente que deberá cumplir las funciones, atribuciones y limitaciones propias del cargo, pero estas se regularán a través de la ley, materializándose la subordinación o dependencia en el principio de jerarquía de la administración (Soto, 2012: 191), que consiste principalmente

\footnotetext{
${ }^{7}$ REAL ACADEMIA ESPAÑOLA (2001) p. 2100.

${ }^{8}$ DIRECCIÓN DEL TRABAJO, Ordinario n ${ }^{\circ} 5299 / 0249$, de 14.09 .1992

${ }^{9}$ Respecto a este concepto, desde la óptica de la normativa internacional, el Convenio 151, de la Organización Internacional del Trabajo, Sobre la protección del derecho de sindicación y los procedimientos para determinar las condiciones de empleo en la Administración Pública, ratificado por nuestro país, señala en su artículo $1 \mathrm{n}^{\mathrm{o}}$ 1, que "El presente Convenio deberá aplicarse a todas las personas empleadas por la Administración Pública, en la medida en que no les sean aplicables disposiciones más favorables de otros convenios internacionales del trabajo." Consiguientemente, establece en su artículo $2^{\circ}$ que "A los efectos del presente Convenio, la expresión empleado público designa a toda persona a quien se aplique el presente Convenio en conformidad al artículo 1.". Por lo tanto, la noción de empleado público incluiría a los empleados municipales.
} 
en la obligación que tiene el funcionario de obedecer las órdenes e instrucciones de las jefaturas. ${ }^{10}$

Adicionalmente, existen otras particularidades en el trabajo público importantes de destacar, como por ejemplo la finalidad de la contratación, que apunta a la consecución del interés público y el bien común; el origen y la manifestación en la ley de las funciones desempeñadas por los empleados, existiendo un quiebre con el trabajo privado al reglamentarse su procedencia; y por último, el hecho que la contraprestación a que está obligada la Administración se realiza con fondos públicos destinados por vía legal, limitándose la libertad de fijar remuneraciones.

Ahora bien, indistinto de la denominación relativa a la subordinación o dependencia, la asimetría en la relación laboral genera la necesidad de tutela de la parte considerada débil, consagrándose por esta razón derechos mínimos en el Código del Trabajo o en el Estatuto Administrativo, situación que no ocurriría en el caso de un vínculo jurídico que se fundamenta en la igualdad de los contratantes, como sucedería en la contratación a honorarios, en donde las partes se autoregulan libremente.

En este sentido, en el caso de los trabajadores a honorarios municipales debemos destacar lo establecido en el artículo $4^{\circ}$ de la Ley $\mathrm{N}^{\circ} 18.883$, el que señala que "Las personas contratadas a honorarios se regirán por las reglas que establezca el respectivo contrato y no les serán aplicables las disposiciones de este Estatuto." Esta situación implica que el estatuto se desliga, normativamente, de estos trabajadores siendo sólo aplicables las disposiciones de sus propios contratos y supletoriamente las normas generales del Código Civil.

\section{EFECTOS DE LA CONTRATACIÓN A HONORARIOS ANÓMALA.}

Pese a lo precedentemente expuesto, este trabajo se centra en la siguiente interrogante: ¿Qué sucede con los trabajadores a honorarios en régimen de subordinación o dependencia?

En términos generales, podemos señalar que a los trabajadores a honorarios no se les han reconocido derechos laborales individuales como feriados legales, indemnización por años de servicio, permisos para ausentarse del trabajo, estabilidad laboral, etcétera. Esta situación resulta más preocupante en el caso de las mujeres contratadas bajo esta modalidad, a quienes no se les ha reconocido derecho a pre y post-natal, lo que implica un menoscabo a la planificación de vida familiar y al desarrollo pleno de sus aspiraciones laborales, circunstancia que estimamos atentatoria contra la dignidad humana tanto en el ámbito laboral como en los derechos reproductivos.

Ante la gravedad de esta situación, en diciembre de 2014 por iniciativa del diputado Bernardo Berger, se propuso a la Presidenta - mediante un proyecto de acuerdo - iniciar el

\footnotetext{
${ }^{10}$ Este principio se encuentra consagrado en los artículos 7 de LOCBGAE; artículo 3, y 61 letras d) y f) de la ley $\mathrm{N}^{\mathrm{o}} 18.834$, Estatuto Administrativo; y el artículo 5, y 58 letras d) y f) de la ley $\mathrm{N}^{\mathrm{o}} 18.883$, Estatuto Administrativo para Funcionarios Municipales
} 
camino para garantizar derechos mínimos a los trabajadores a honorarios, tales como feriado anual de 15 días; permiso por 6 días como símil a los días administrativos; uso de licencias médicas; subsidio pre y post natal, entre otros. Esta situación muestra el difícil panorama que afecta a los trabajadores a honorarios en materia derechos individuales y de seguridad social; en este último punto implica, a lo menos, la inobservancia del Pacto Internacional de Derechos Económicos Sociales y Culturales, en su artículo 9 ; y del Convenio $N^{\mathrm{o}} 187$ de la Organización Internacional del Trabajo sobre el marco promocional para la seguridad y salud en el trabajo.

La seguridad social es una materia de especial importancia puesto que permite atender las necesidades de subsistencias de la población y ampararlas frente a imprevistos (Ghai, 2003: 125). Medidas como la homologación de la situación que atraviesan los trabajadores a honorarios con la de trabajadores independientes, tras la promulgación de la Ley N N $^{\circ} 0.255$ que establece Reforma Previsional, estimamos resultan erróneas debido a las diferencias fácticas en la generación de recursos entre el trabajador independiente y el trabajador a honorarios bajo subordinación y dependencia.

Sobre este aspecto, el Sindicato Independiente de Trabajadores a Honorarios de la Ilustre Municipalidad de Maipú, en el año 2011, expuso a la Comisión de Trabajo y Seguridad Social de la Cámara de Diputados:

"Pero lo que resulta finalmente reprochable, es que finalmente serán los propios trabajadores a honorarios los que deberán costear estos beneficios -vía retención de impuestos y descuentos previsionales-, incluso las eventualidades de la cesantía; no considerándose el aporte que por años han venido entregando a través de su desempeño laboral precario, con un Estado que hoy en día registra un superávit de US \$2.721 millones; parte de lo cual, es posible por la mantención de esta vergonzosa situación de estos trabajadores, contraria a la jurisprudencia internacional, en la que el Estado impone deberes, pero no reconoce derechos, aún cuando resulta en ser el principal empleador de este sector" (Sindicato Independiente de Trabajadores Honorarios de la Ilustre Municipalidad de Maipú, 2011: 7)

Adicionalmente, es importante considerar otro ámbito de la contratación a honorarios anómala: el reconocimiento de derechos colectivos. En la actualidad asistimos a un crecimiento cuantitativo de los sindicatos a honorarios y con altos grados de articulación, circunstancia que se ve relejada en la creación de la Unión de Trabajadores a Honorarios Municipales de Chile ${ }^{11}$, primera organización de hecho que agrupó a sindicatos del sector y que, posteriormente, se transformaría en parte de la Unión Nacional de Trabajadores Públicos a Honorarios de $\mathrm{Chile}^{12}$, conformada actualmente por organizaciones a nivel central y local de la Administración.

Así las cosas, estos trabajadores a honorarios, aunque han hecho efectivo el derecho de sindicalización configurándose con esto el ejercicio de la faz orgánica de la libertad sindical (Caamaño, 2008: 274), se enfrentan a la dificultad de que sus organizaciones no se constituyen formalmente en razón de un empleador, como sucedería en las asociaciones de

\footnotetext{
${ }^{11}$ Véase en REVISTA BAGUAL (2014).

${ }^{12}$ Véase en CENTRAL UNITARIA DE TRABAJADORES (2014).
} 
funcionarios o de sindicatos empresa o interempresa, generando un impacto directo en su funcionamiento cotidiano y en los otros componentes de la faz funcional de la libertad sindical; la negociación colectiva ${ }^{13}$ y la huelga.

Pese a no reconocerse formalmente la figura del empleador, los trabajadores a honorarios han realizado movilizaciones de índole colectiva e incluso con esfuerzos de cobertura nacional; el 3 de septiembre de $2014^{14}$ diversas organizaciones del sector municipal realizaron jornadas de protestas para visibilizar la problemática que los aquejaba a nivel país y se han intentado replicar este tipo de movilizaciones en otras oportunidades, como el 9 de octubre del año $2015^{15}$.

Adicionalmente, a nivel local algunas organizaciones de trabajadores a honorarios han realizado negociaciones para establecer contratos marcos de prestación de servicios aplicables a sus afiliados y garantes de ciertos derechos mínimos; no obstante, debemos advertir que el cumplimiento de estos acuerdos dependerá finalmente del edil de turno, puesto que su inobservancia se ventilaría en sede civil, a través de una acción por incumplimiento contractual, lo que trae aparejado inconvenientes económicos y de tiempo que podrían desincentivar estas instancias de democratización laboral.

Ahora bien, debemos señalar que esta problemática no solo generará efectos nocivos para los trabajadores a honorarios sino que existen también efectos mediatos para la comunidad, en consideración que se pone en jaque la estabilidad de las funciones de la Municipalidad o la Administración Central en procesos de movilización.

Como consecuencia de la desprotección laboral que afecta a estos trabajadores, los grados de conflictividad laboral han ido en aumento en este sector, encontrándose esta circunstancia reflejada en las movilizaciones ocurridas en la Administración Central y que perfectamente podrían verificarse en municipios. A modo de ejemplo, el 22 de abril de $2016^{16}$, los trabajadores a honorarios del Ministerio de Vivienda y Urbanismo y del Servicio de Vivienda y Urbanización, realizaron una movilización nacional que afectó el normal desarrollo de las funciones de la cartera y del servicio, lo que permitió observar la fragilidad de la continuidad de labores en estos escenarios.

Lamentablemente, situaciones como la descrita en el caso de la Municipalidades, resultan preocupantes puesto que los trabajadores a honorarios, como se demostrará, se han convertido en la masa laboral mayoritaria a causa de la utilización excesiva de esta forma de contratación, pese a que autoridades de gobierno y legislativas han tomado conocimiento del uso irregular de esta contratación.

\footnotetext{
${ }^{13}$ A las Asociaciones de Funcionarios igualmente no se les reconoce este derecho, sin embargo, consideramos que trabajadores a honorarios se encuentran en una posición aún más desmejorada. En términos legales las Asociaciones realizan movilizaciones en consideración a que la Administración es su empleador y, en dicha circunstancia, se les garantiza cierta protección legal mínima, por ejemplo, a través del artículo $25^{\circ}$ de la Ley $\mathrm{N}^{\circ}$ 19.296, que consagra el fuero de los representantes de los funcionarios, otorgándose garantías en los procesos de diálogo con la Administración. Esta situación no ocurre en el caso de los sindicatos de trabajadores a honorarios, quienes al no tener formalmente empleador no se les reconoce protección legal para participar en instancias de esta índole.

${ }^{14}$ Véase ASEMUCH (2014).

${ }^{15}$ Véase RADIO BIOBIO (2015)

${ }^{16}$ Véase en RADIO BIOBIO (2016).
} 
En este sentido, según consta en la Historia de la Ley $\mathrm{N}^{\circ} 19.280$, que modifica Ley $\mathrm{N}^{\mathrm{o}}$ 18.695, Orgánica Constitucional de Municipalidades, y establece normas sobre plantas de personal de las municipalidades, del año 1993, la Senadora Olga Feliú Segovia manifestó:

“La señora FELIÚ.- Señor Presidente, aquí se ha reiterado el concepto de que el a honorarios sería una especie de personal suplementario del de planta y a contrata. En verdad, eso es falso. Los contratados sobre la base de honorarios son para desempeñar labores accidentales y no habituales. Eso es lo que autoriza la ley, y no algo distinto."17

Habiéndose superpuesto la práctica de la contratación anómala y en consideración a los efectos precedentemente expuestos, podemos señalar que se ha erigido la idea de la Administración como fuente de empleo precario (Palavecino, 2000), debiendo comprenderse esto a la luz de lo referido por la Dirección del Trabajo en su cuaderno de investigación número 30, "Lejos del trabajo decente", en el que se caracteriza con trabajos menos estables y que conforman una periferia al margen de toda protección y garantía laboral (Henríquez y Riquelme, 2006: 16). Por contrapartida, la Organización Internacional del Trabajo refiere qué debemos entender por trabajo decente; el que está supeditado a elementos tales como la existencia de empleo, remuneraciones, seguridad en el trabajo, condiciones salubres, seguridad social, seguridad en los ingresos (Ghai, 2003: 126), circunstancias que se encuentran en crisis en esta forma de contratación.

\section{MAGNITUD DE LA PROBLEMÁTICA EN EL PLANO MUNICIPAL.}

Los datos que se aportan a continuación nos permiten dotar de contenido cuantitativo la presente problemática y demostrar la sobreutilización del mecanismo de contratación a honorarios. Por la extensión de este trabajo solo entregaremos los datos que consideramos de mayor importancia o más ejemplificadores de la magnitud del problema ${ }^{18}$, teniendo en cuenta - a partir de las afirmaciones realizadas con anterioridad - que se trata de una masa laboral mayoritaria y que esta se centra en la modalidad programas comunitarios.

La recolección de datos fue realizada desde el Sistema Nacional de Información Municipal (SINIM), perteneciente a la Subsecretaría de Desarrollo Regional y Administrativo. Las Municipalidades tienen la obligación legal de entregar a dicha Subsecretaría información oportuna con la finalidad de mejorar la gestión y cumplir con los estándares de transparencia requeridos para la Administración Pública en general, según se dispone en la Ley $\mathrm{N}^{\circ} 20.237$ y Ley $\mathrm{N}^{\circ} 19.602$.

Los resultados a nivel nacional son sorprendentes, considerando que de un total de 346 Municipalidades a nivel país, existen un total de 88.629 funcionarios que prestan

\footnotetext{
${ }^{17}$ CONGRESO NACIONAL DE CHILE (1993) p.266.

${ }^{18}$ Para un análisis con mayor profundidad, véase Neira Reyes, Francisco y Rojas Muñoz. Álvaro (2015). Los Trabajadores a Honorarios de la Administración Municipal: Su desregulación como vulneración al Orden Público Laboral. Los datos utilizados en el presente artículo han sido actualizados a las últimas cifras disponibles
} 
servicios para los municipios y que 26.589 corresponden a funcionarios de planta, 12.408 a contrata y 49.632 trabajadores a honorarios.

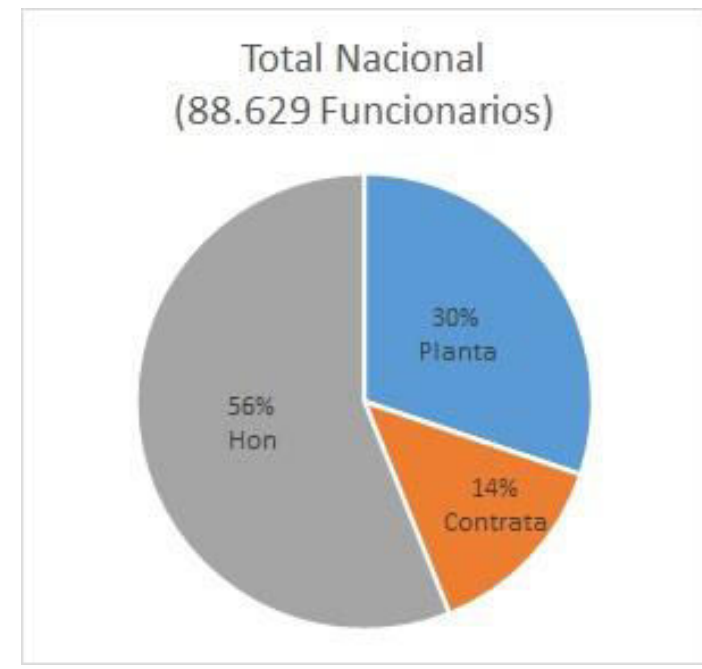

\section{Grafico $n^{\circ} 1$.}

Más de la mitad de las personas que prestan servicios al interior de las Municipalidades del país, lo realiza bajo la modalidad de contratación a honorarios, siendo 49.632 prestadores de servicios.

Gráfico $n^{\circ} 2$.

En las capitales regionales la modalidad de contratación a honorarios implica 5496 prestadores de servicios.

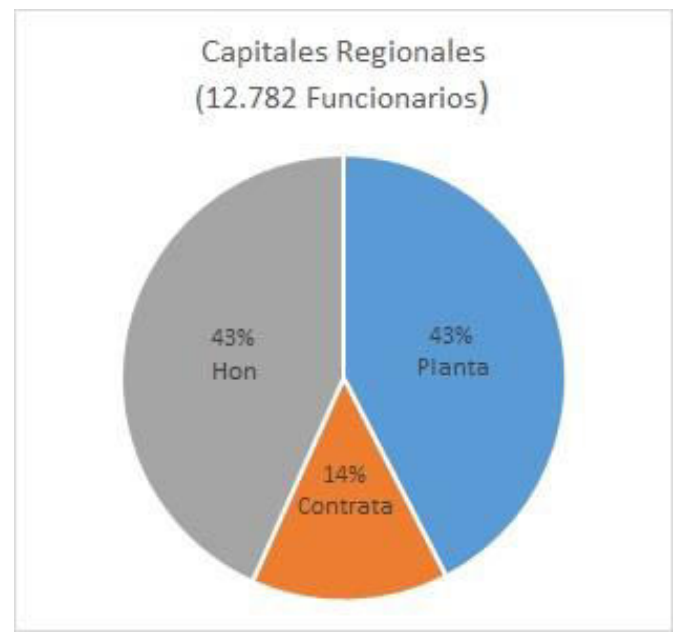

Municipios con 50 o menos funcionarios

(42 Comunas - 1387 Funcionarios)

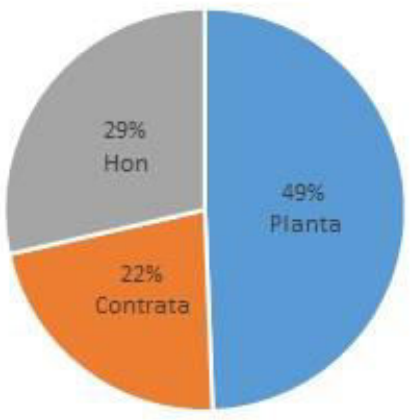

Grafico $n^{\circ} 3$.

En municipios con menos de 50 funcionarios la contratación a honorarios es menor a la de planta, sin embargo, esta no reviste un carácter marginal y representa 402 prestadores de servicios. 


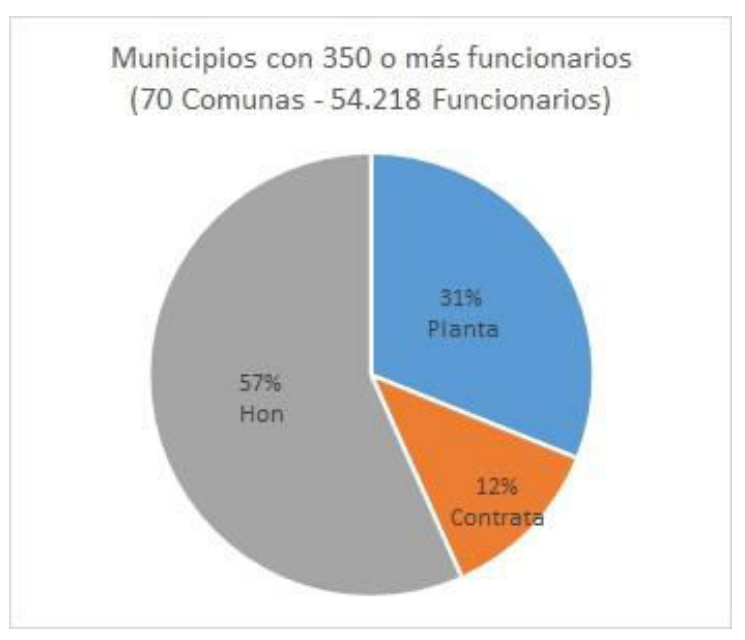

Gráfico $N^{\circ} 4$.

En municipios con más de 350 funcionarios, es mayoritario el porcentaje de quienes desempeñan funciones a honorarios, siendo 30.904 prestadores de servicios.

Tabla 1.

\begin{tabular}{|r|r|r|r|r|r|r|}
\hline Año & Planta & Contrata & $\begin{array}{l}\text { Honorarios } \\
\text { Suma } \\
\text { Alzada }\end{array}$ & $\begin{array}{l}\text { Honorarios } \\
\text { Programas } \\
\text { Comunitarios }\end{array}$ & $\begin{array}{l}\text { Total } \\
\text { Honorarios }\end{array}$ & $\begin{array}{l}\text { Fotal } \\
\text { Funcionarios } \\
\text { Municipales }\end{array}$ \\
\hline 2012 & 26.049 & 10.511 & 5.633 & 32.409 & 38.042 & 74.602 \\
\hline 2013 & 26.094 & 10.700 & 6.585 & 34.279 & 40.864 & 77.658 \\
\hline 2014 & 26.315 & 11.021 & 8.445 & 37.423 & 45.686 & 83.204 \\
\hline 2015 & 26.742 & 12.186 & 10.319 & 39.382 & 49.701 & 88.629 \\
\hline
\end{tabular}

Merece especial atención la concentración de honorarios en programas comunitarios, los que son la mayoría del personal que se desempeña en los municipios.

Cabe destacar que, en la generalidad de los municipios, existe un alto porcentaje de contratación a honorarios, la que varía en promedio entre el $45 \%$ y el 55\% del total de la dotación. El aumento en la dotación de personal en las Municipalidades se ha debido principalmente al incremento de los trabajadores a honorarios, en especial aquellos contratados en la modalidad de "programas comunitarios" la que, según revisaremos, tiene menos exigencias en su procedencia y no se computa en el límite porcentual de la contratación a honorarios.

De los datos extraídos podemos concluir que los trabajadores a honorarios han permitido aumentar la cobertura de los servicios municipales, reflejándose con mayor intensidad en fenómenos de expansión demográfica. En este sentido, en Municipalidades en donde ha aumentado la población y ha surgido la necesidad de ampliar la dotación municipal, el aumento de funcionarios de planta o contrata no se compara con el crecimiento explosivo de los trabajadores a honorarios (62\% La Florida, 81\% Maipú, 84\% Puente Alto). 
De las cifras expuestas es posible revelar la magnitud de esta problemática, la que resulta preocupante por los niveles porcentuales de esta contratación y por la cantidad de personas que se encuentran en esta situación, quedando en evidencia una anomalía preocupante: la mayoría de las tareas que por ley deben cumplir los municipios están siendo realizadas por trabajadores que, en teoría y en su mayoría, no debiesen prestar servicios de duración permanente.

\section{LA PRESTACIÓN DE SERVICIOS AL INTERIOR DE LAS MUNICIPALIDADES.}

Para comprender las razones que explican la magnitud de la contratación a honorarios, estimamos pertinente revisar de forma exhaustiva la normativa vigente en la materia y la interpretación que se ha hecho de ella, principalmente por la Contraloría General de la República, la que a través de sus dictámenes busca fijar el sentido y alcance de la legislación administrativa, en este caso del artículo $4^{\circ}$ de la Ley $\mathrm{N}^{\circ} 18.883$, que se transcribe a continuación:

"Podrán contratarse sobre la base de honorarios a profesionales y técnicos de educación superior o expertos en determinadas materias, cuando deban realizarse labores accidentales y que no sean las habituales de la Municipalidad; mediante decreto del alcalde. Del mismo modo se podrá contratar, sobre la base de honorarios, a extranjeros que posean título correspondiente a la especialidad que se requiera.

Además, se podrá contratar sobre la base de honorarios, la prestación de servicios para cometidos específicos, conforme a las normas generales.

Las personas contratadas a honorarios se regirán por las reglas que establezca el respectivo contrato y no les serán aplicables las disposiciones de este Estatuto."

La necesidad del análisis sistemático del ordenamiento jurídico nos obliga a considerar lo consagrado en la Ley $\mathrm{N}^{\mathrm{o}} 18.834$ sobre Estatuto Administrativo, teniendo presente que en su artículo $11^{\circ}$ tiene incluso una redacción idéntica a la norma precedentemente transcrita. $^{19}$

\subsection{TIPOS DE LABORES FACULTADAS POR LA LEGISLACIÓN PARA SER DESARROLLADAS POR LOS TRABAJADORES A HONORARIOS MUNICIPALES}

Considerando el artículo $4^{\circ}$ de la Ley $\mathrm{N}^{\circ} 18.883$, es posible establecer dos tipos de labores: i) generales, cuando se trata de cumplir labores accidentales y no habituales de la

\footnotetext{
${ }^{19}$ La Contraloría General de la República se ha referido a ambos estatutos en iguales términos, lo que demuestra que son entendidos de forma similar: "si bien las personas contratadas a Honorarios no se rigen por las leyes 18.834 o 18.883, Estatuto Administrativo y Estatuto Administrativo para Funcionarios Municipales, respectivamente, es posible concederles análogos derechos o beneficios que los establecidos para los servidores a quienes sí se les aplican esos textos legales(...)" (Véase en CONTRALORÍA GENERAL DE LA REPÚBLICA, Dictamen N²9.501, de 14.7.2003 y Dictamen $\mathrm{N}^{\circ} 14.471$, de 20.3.2004)
} 
Municipalidad; ii) excepcionales, en el caso de contratación a honorarios para desarrollar cometidos específicos propios de las tareas habituales y permanentes del municipio.

Cabe destacar que la Contraloría General de la República ha señalado que el fundamento en este tipo de contratación, surge de la necesidad de contar con la asesoría de especialistas en determinadas materias relacionadas con las funciones propias del respectivo servicio. ${ }^{20}$ Así las cosas, se pueden contratar a honorarios a profesionales, técnicos o expertos sean estos chilenos o extranjeros, entendiéndose que reúnen estas calidades quienes poseen los títulos respectivos de acuerdo al art. 31 de la Ley $\mathrm{N}^{\circ} 18.962$ Orgánica Constitucional de Enseñanza. Adicionalmente, se considera también expertos a aquellos que, sin ostentar necesariamente tales títulos, poseen especial conocimiento de una materia, dada su práctica, habilidad o experiencia en la misma, la que debe acreditarse mediante documentación fidedigna. ${ }^{21}$

\subsubsection{CONTRATO A HONORARIOS PARA EL DESEMPEÑO DE LABORES ACCIDENTALES Y NO HABITUALES DE LA MUNICIPALIDAD.}

La Contraloría General de la República, en reiteradas ocasiones, ha sostenido que las labores accidentales y no habituales son "aquellas que siendo propias de la Municipalidad, son ocasionales, es decir, circunstanciales y distintas de las realizadas por el personal de planta o a contrata". (Contraloría, 2004, Dictamen $\mathrm{N}^{\circ}$ 18.347)

Es preciso señalar que este tipo de contratación posee regulación específica, en el Decreto No 98 de 1991, del Ministerio de Hacienda, que Establece Modalidades a que Deberá Ajustarse la Celebración de Convenios que involucren la Prestación de Servicios Personales. En esta normativa, se consagra en su artículo $2^{\circ}$ que "por decreto supremo fundado del Ministerio correspondiente, podrá contratarse a profesionales, técnicos o expertos, de alta especialización, para labores que, por su naturaleza, no sean susceptibles de ser asimiladas a posiciones de la Escala Única de Sueldos, sobre la base de honorarios consistente en una suma alzada u otro sistema cuando se contrate a profesionales".

Adicionalmente, el artículo $3^{\circ}$ de la normativa del Decreto $N^{\circ} 98$ de 1991, establece una serie de requisitos de este tipo de contratación en caso en que se celebre con personas naturales: “a) La prestación que se contrate debe ser indispensable para la ejecución eficiente de las funciones que son propias del organismo; b) que no pueda lograrse por medio de recursos humanos propias de la institución; c) la entidad contratante deberá contar con las disponibilidades presupuestarias suficientes para financiar el pago de los honorarios."

En igual sentido, el Decreto Ley $\mathrm{N}^{\circ} 1.608$ de 1976, que Dicta normas para implantar la segunda etapa de la Carrera Funcionaria y otras disposiciones, en su artículo $13^{\circ}$, hace referencia a la contratación en base a honorarios de profesionales, técnicos o expertos, estableciendo como norma excepcionalísima la posibilidad de contratar hasta 15 personas para que realicen labores permanentes y habituales del servicio o institución asignados,

\footnotetext{
${ }^{20}$ CONTRALORÍA GENERAL DE LA REPÚBLICA, Dictamen $\mathrm{N}^{\circ}$ 16.220, de 20.5.1982.

${ }^{21}$ CONTRALORÍA GENERAL DE LA REPÚBLICA, Dictamen N 18.347, de 18.4.2004.
} 
para la Junta de Gobierno y para cada Ministerio. Además, se autoriza la contratación de hasta 15 personas para labores de asesoría altamente calificadas, debiendo en ambos casos cumplir con lo establecido en el artículo 33 del Decreto Ley $\mathrm{N}^{\circ} 249$ de 1974, que Fija la escala única de sueldos para el personal. El propio Decreto Ley $\mathrm{N}^{\circ} 1.608$ de 1976 , en su artículo $13^{\circ}$, establece que las contrataciones que se efectúen de acuerdo a las causales establecidas en dicho artículo, no podrán exceder la dotación máxima asignada al servicio respectivo.

De la normativa expuesta se observa el carácter marginal del contrato a honorarios. En sintonía con dichas estipulaciones, la Contraloría General de la República, ha dado cuenta del carácter excepcional de este mecanismo y de la hipótesis en comento: "De conformidad a lo prescrito en los arts. 3 y 11 de la Ley $\mathrm{N}^{\circ} 18.834$, y 3,4 y 5 de la Ley $\mathrm{N}^{\circ} 18.883$, el legislador ha confiado la ejecución de las tareas necesarias para cumplir las funciones públicas que la ley asigna a cada institución, en primer lugar, a la dotación permanente de la misma, constituida por los funcionarios de planta; luego, a aquella dotación transitoria, esto es, a los empleados a contrata y, finalmente, de manera excepcional y restringida, a quienes sirven labores en calidad de contratados a honorarios." (Contraloría, 2005, Dictamen $\mathrm{N}^{\circ} 25.694$ y Contraloría, 2005, Dictamen $\mathrm{N}^{\circ} 7.023$ )

\subsubsection{CONTRATACIÓN A HONORARIOS PARA DES ARROLLAR COMETIDOS ESPECÍFICOS PROPIOS DE LAS TAREAS HABITUALES Y PERMANENTES DEL MUNICIPIO}

La Ley $\mathrm{N}^{\circ} 18.883$, en su artículo $4^{\circ}$ inciso $2^{\circ}$, faculta una contratación a honorarios aún más excepcionalísima que la recién expuesta, facultándose convenir la realización de cometidos específicos sobre labores permanentes o habituales de la Municipalidad. De la lectura de la norma se desprenden una serie de requisitos de este tipo de contratación, los que han sido tratados por la jurisprudencia administrativa dotando su contenido y alcance.

En primer lugar, como requisito sine qua non, las tareas efectuadas bajo este tipo de contratación deben comprender solamente cometidos específicos. A este respecto, el órgano contralor ha señalado que deben "determinarse de manera puntual, individualizadas en forma precisa." 22 ; "Por tanto, no se ajustará a derecho la simple enumeración de labores a desarrollar, ni la contratación a honorarios de una persona para que desempeñe labores genéricas." 23 Así las cosas, la utilización del término "asesorar" como objeto de un contrato a honorarios, no cumple con la característica de precisión y determinación exigida por ley, al tratarse de una expresión amplia y ambigua de alcance genérico que no establece ninguna labor en particular. ${ }^{24}$

En segundo lugar, otro requisito interpretado por la Contraloría General de la República, es relativo al conocimiento o especialización que debe tener el trabajador a honorarios, señalando que estos “....deberán tener alguna de las calidades a que alude el

\footnotetext{
${ }^{22}$ CONTRALORÍA GENERAL DE LA REPÚBLICA, Dictamen n 40.021, de 2.11.1998.

${ }^{23}$ CONTRALORÍA GENERAL DE LA REPÚBLICA, Dictamen n ${ }^{\circ}$ 57.217, de 6.12.2005.

${ }^{24}$ CONTRALORÍA GENERAL DE LA REPÚBLICA, Dictamen n 45.711, de 05.12.2001.
} 
inciso primero de este mismo art. 11, esto es, poseer la condición de profesionales y técnicos de educación superior o ser expertos en determinada área o materia."(Contraloría, 1999, Dictamen $\mathrm{N}^{\circ}$ 44.597)

En tercer lugar, se establece como requisito el carácter temporal de este tipo de prestación de servicios, manifestándose por parte de la jurisprudencia administrativa que: “(...) Tampoco configuran cometidos específicos si se contrata por periodos cortos, reiterados sucesivamente. Esta prestación de servicios personales debe ser excepcional y eminentemente transitoria, puesto que la condición de cometido específico se pierde con su reiteración en el tiempo, en que pasa a transformarse en una labor permanente y, por tanto, habitual. La reiteración periódica de estos cometidos específicos desvirtúa la existencia misma de la excepción $y$, finalmente, conlleva a una desviación de facultades." (Contraloría, 2003, Dictamen No 20.045).

Por último, el ente contralor advierte el límite de esta contratación, señalando que "la atribución de contratar personal a honorarios no puede significar que el órgano público llegue a desarrollar indefinidamente sus labores habituales, utilizando los servicios de personas contratadas conforme a esta modalidad, pues para tales fines el ordenamiento jurídico contempla las dotaciones de personal de planta y los empleados a contrata." , agregando que "si una entidad pública necesita recurrir a los contratos a honorarios por la inadecuada composición de su planta personal y por el incremento del volumen y complejidad de tareas que han llegado a ser permanentes, le corresponde gestionar las modificaciones estatutarias o de presupuesto que requiera su funcionamiento" (Contraloría, 2005, Dictamen $\mathrm{N}^{\circ}$ 57.217).

\subsection{MODALIDADES DE CONTRATOS Y PRESUPUESTO MUNICIPAL}

Los municipios poseen distintas modalidades de contratación de trabajadores a honorarios - circunstancia distinta a las labores que según hemos revisado puede desempeñar un trabajador a honorarios - las que se diferencian según la partida asignada en el presupuesto municipal anual. En este sentido, el artículo 11 del Decreto Ley $\mathrm{N}^{\circ} 1.263$, Orgánica de Administración Financiera del Estado de 1975, establece que "el presupuesto del Sector Público consiste en una estimación financiera de los ingresos y gastos de este sector para un año dado, compatibilizando los recursos disponibles con el logro de metas y objetivos previamente establecidos."

En el caso de la Administración Municipal, el presupuesto requiere ser aprobado por el Alcalde previo acuerdo del Concejo Municipal, en virtud de lo establecido en el artículo 65 a), de la Ley $\mathrm{N}^{\circ} 18.695$, el que se regirá además, al igual que todo presupuesto del sector público, por el Decreto Ley $N^{\circ} 1.263$ y por el Decreto $\mathrm{N}^{\circ} 854$, del Ministerio de Hacienda de 2004.

Ahora bien, el Decreto $N^{\circ}$ 854, del Ministerio de Hacienda de 2004, que Determina las Clasificaciones Presupuestarias, establece aquellos gastos que atañen directamente al objeto de este trabajo, los que se encuentran contenidos en el subtítulo 21 "Gastos en Personal". En el se comprenden todos los gastos que, por concepto de remuneraciones, aportes del empleador y otros relativos al personal, consultan los organismos del sector público. Dentro 
de este subtítulo encontramos cuatro Ítems: 01 Personal de Planta; 02 Personal a Contrata; 03 Otras Remuneraciones; 04 Otros Gastos en Personal.

Respecto de los Ítems reseñados, dos tienen directa implicancia con la contratación a honorarios a través de tres asignaciones particulares: (i) Ítem 03 "Otras Remuneraciones", Asignación 001 "Honorarios a Suma Alzada - Personas Naturales", que la normativa describe como "Honorarios a profesionales, técnicos o expertos en determinadas materias y/o labores de asesoría altamente calificada, de acuerdo con las disposiciones vigentes." (ii) Ítem 03 “Otras Remuneraciones", Asignación 002 "Honorarios Asimilables a Grado". (iii) Ítem 04 "Otros Gastos en Personal", Asignación 004 "Prestaciones de Servicios en Programas Comunitarios", señalando la normativa que "Comprende la contratación de personas naturales sobre la base de honorarios, para la prestación de servicios ocasionales y/o transitorios, ajenos a la gestión administrativa interna de las respectivas Municipalidades, que estén directamente asociados al desarrollo de programas en beneficio de la comunidad, en materias de carácter social, cultural, de rehabilitación o para enfrentar situaciones de emergencias." Esta última asignación fue incorporada por el Decreto $\mathrm{N}^{\mathrm{o}}$ 1.186, del Ministerio de Hacienda de 2007, que Modifica Clasificaciones Presupuestaria.

La clasificación reseñada es de vital importancia para comprender la gran cantidad de trabajadores a honorarios que desempeñan funciones en las Municipalidades y el porcentaje en que se concentran. En este sentido, de las tres asignaciones indicadas anteriormente, solo dos son utilizadas por la Administración Municipal: 1) "Honorarios a Suma Alzada" y 2) "Prestación de Servicios en Programas comunitarios", en las que 8.445 trabajadores corresponden a la modalidad Suma Alzada y 37.423 a programas comunitarios, siendo estos últimos el $82 \%$ de los honorarios municipales y el $45 \%$ del total del personal municipal a nivel nacional.

Ahora bien, la contratación en estas modalidades, como revisaremos a continuación, tiene implicancias significativas tanto en la forma de celebración como en el control de la legalidad.

En el caso de un Contrato a Honorarios a Suma Alzada, resulta necesario que sea aprobado por decreto alcaldicio y fiscalizado por la Contraloría General de la República, en conformidad a las reglas establecidas en la Resolución $\mathrm{N}^{\circ}$ 1.600, que Fija Normas Sobre Exención del Trámite de Toma de Razón, debiendo cumplir en caso de honorarios inferiores de 150 U.T.M, solo con el trámite de registro, en este caso, simplemente bastará enviar los antecedentes originales del acto administrativo en un plazo de 15 días, según consta en la circular $\mathrm{N}^{\circ} 15.700$ de 2012 del organismo fiscalizador.

Adicionalmente, la modalidad Suma Alzada requiere precisar el ítem presupuestario al que se imputa el gasto, teniendo como consecuencia además la necesidad de que el Director de Administración y Finanzas Municipal, certifique el cumplimiento de la regla establecida en el artículo 13 de la Ley $N^{\circ}$ 19.280, que modifica Ley No 18.695, Orgánica Constitucional de Municipalidades, que establece que el gasto presupuestario en honorarios no podrá superar el 10\% de los fondos destinados a los funcionarios de planta.

Por último, en lo referente a esta modalidad de contratación, el Concejo Municipal al momento de aprobar el presupuesto municipal, debe manifestar su acuerdo en relación con 
los objetivos y funciones específicas de la contratación a honorarios, sin perjuicio de la responsabilidad que atañe al alcalde por las contrataciones individuales. ${ }^{25}$

En lo relativo a la modalidad de prestación de servicios en programas comunitarios, la situación es radicalmente distinta y permite explicar la gran cantidad de personas afectas al régimen de contratación a honorarios.

La contratación bajo esta modalidad es aprobada por el Alcalde a través de decreto exento, es decir, no se genera toma de razón obligatoria por parte de la Contraloría General de la República, sin perjuicio del trámite de Registro, en consideración a que el control recae propiamente sobre el programa comunitario y a los recursos que se le destinan. En este sentido, el Concejo Municipal al aprobar el presupuesto anual, a diferencia de lo que ocurre con la modalidad Suma Alzada, no da su aquiescencia respecto de las funciones u objetivos de la contratación, limitándose simplemente a visar el programa en el que estarán implicados los trabajadores a honorarios y el gasto del respectivo ítem presupuestario.

Sin embargo, estimamos que lo más peculiar de esta modalidad de contratación es que pese a ser trabajadores a honorarios que se desempeñan al interior de las Municipalidades, estos no son incluidos en la aplicación de la regla del artículo 13 de la Ley $\mathrm{N}^{\circ} 19.280$, arguyéndose que se trata de recursos económicos asociados al programa comunitario. En este sentido, la jurisprudencia administrativa ha señalado que: "estos gastos no son parte de la provisión de personal, siendo esta la misma razón por la cual no considera obligatorio fiscalizar directamente estos contratos." (Contraloría, 2009, Dictamen $N^{\circ}$ 58.743). Por esta razón, se establece como exigencia del decreto exento aprobatorio, la indicación precisa del programa al que se encuentra vinculado el trabajador a honorarios e idealmente si la contratación se genera con recursos de otros organismos de la Administración Pública.

En este sentido, esta modalidad tiene la particularidad de que los recursos provienen en muchas ocasiones de Ministerios $\mathrm{u}$ otro organismo de la Administración Central, no tratándose de recursos propios de las Municipalidades, siendo estas administradoras y ejecutoras de los mismos. Por lo tanto, enfrentamos una relación triangular entre la Administración Municipal, la Administración Central y la persona natural o jurídica contratada, lo que aparentemente ha generado de forma indirecta, que la problemática no se aborde claramente desde la Administración Central o Municipal.

Por último, debemos señalar que en esta modalidad se establece un quiebre respecto a las exigencias expuestas en la presente investigación, señalando la Contraloría General de la República elementos precisos para constatar la legalidad de la contratación a honorarios bajo esta vía, refiriendo que "los gastos comprendidos en la aludida cuenta presupuestaria son aquellos que derivan de las contrataciones a honorarios de personas naturales que tengan por objeto la prestación de servicios que reúnan las siguientes características: a) que sean ocasionales y/o transitorios; b) que sean ajenos a la gestión administrativa interna de las respectivas Municipalidades y c) que se encuentren directamente asociados al desarrollo de programas en beneficio de la comunidad, en materias de carácter social, cultural, deportivo, de rehabilitación o para enfrentar situaciones de emergencia, desarrollados en

${ }^{25}$ CONTRALORÍA GENERAL DE LA REPÚBLICA, Dictamen $\mathrm{N}^{\circ}$ 7.266, de 10.2.2005; y Dictamen $\mathrm{n}^{\circ}$ 14.064, de 1.3.2013. 
cumplimiento de las funciones previstas en el artículo $4^{\circ}$ de la ley $\mathrm{N}^{\circ} 18.695$ Orgánica Constitucional de Municipalidades (funciones que podrán desarrollar directamente o con otros órganos de la Administración)." (Contraloría, 2012, Dictamen № 31.394)

En este sentido, el quiebre se produce al no exigirse por parte del órgano contralor la especificidad de las labores de la contratación ${ }^{26}$, destacándose solamente las ideas generales de transitoriedad y ocasionalidad. No obstante, nos parece igualmente cuestionable el cumplimiento de esta exigencia, debido a que la duración de la prestación de servicios se circunscribe al programa, por tanto, la transitoriedad finalmente es un elemento permanente en estas iniciativas cubriendo su total duración y, en muchas ocasiones, al ser financiadas desde la Administración Central, tras finalizar un programa los trabajadores son trasladados a otro municipio para replicar idéntica iniciativa, justificándose la ocasionalidad solamente en la suscripción de un nuevo convenio a honorarios.

En resumen, en esta modalidad de contratación, el órgano contralor no exige determinar la función específica que deberá cumplir el trabajador a honorarios, bastando señalar el programa al que están destinados; los trabajadores no se computarán para efectos de imputar gasto en conformidad del artículo 13 de la Ley $\mathrm{N}^{\circ} 19.280$ y, por último, se celebraran a través de decretos exentos por parte del alcalde, bastando solamente el trámite de registro ante la Contraloría General de la República y la aprobación del programa por parte del Concejo Municipal.

\section{LA APLICACIÓN DE LA NORMATIV A LABORAL A LOS TRABAJADORES A HONORARIOS DE LA ADMINISTRACIÓN.}

Analizando la problemática desde la premisa de una prestación de servicios anómala en que existe subordinación o dependencia, debemos advertir que se encuentran implicadas tres normativas; Código del Trabajo; Ley $\mathrm{N}^{\circ}$ 18.883, Estatuto Administrativo de Funcionarios Municipales; y Código Civil. Respecto a estos dos últimos, consideramos que no resultan aplicables para abordar la problemática de los trabajadores a honorarios. En el caso del artículo $1^{\circ}$, de la Ley $\mathrm{N}^{\mathrm{o}} 18.883$, existe exclusión expresa para su aplicación; respecto del Código Civil, entendemos que su aplicación apunta a un carácter meramente formal y no se justifica en las consideraciones ontológicas del conflicto.

Sin perjuicio de ello, durante mucho tiempo la aplicación del Código Civil fue la tendencia mayoritaria en nuestros tribunales, posición que ha logrado ser cuestionada en el último tiempo a través de un giro en la jurisprudencia ${ }^{27}$ que ha sentado las bases de la aplicación como norma tutelar del Código del Trabajo. De forma simultánea existe un fallo

\footnotetext{
${ }^{26}$ Interpretación cuestionable pues instala una práctica que permite eludir las exigencias establecidas por ley. Cabe destacar que, a través del Decreto $\mathrm{n}^{\circ} 1.186$, del Ministerio de Hacienda, el ejecutivo en uso de su potestad reglamentaria, ha establecido una asignación de contratación a honorarios nueva y que formalmente no se encuentra vinculada a los recursos económicos de la municipalidad. Sin embargo, como es de toda lógica, ni el uso de esta potestad ni que la contratante sea la Municipalidad o el Gobierno Central, puede implicar la elusión de los requisitos impuestos por el legislador, debiéndose por tanto; especificar las labores a desempeñar y prohibir la realización de funciones previstas en el artículo $4^{\circ}$, de la Ley $\mathrm{N}^{\mathrm{o}}$ 18.695.

${ }^{27}$ Esta idea ha sido expuesta en columna del diario Mercurio legal: VERGARA (2016)
} 
contrario a esta posición, el que reafirma faliblemente la aplicación del Código Civil ${ }^{28}$, lo que nos merece preocupación en virtud de las consideraciones jurídicas que expondremos.

Es importante referir las principales razones argüidas por quienes estiman aplicable el Código Civil; se señala que la remisión normativa realizada al contrato a honorarios en el inciso final del artículo $4^{\circ}$ de la Ley $\mathrm{N}^{\mathrm{o}}$ 18.883, es imperativa para la Administración y excluye la aplicación de otro estatuto que no fuese el común; que el legislador ha determinado en la propia Ley $\mathrm{N}^{\mathrm{o}} 18.883$, los casos en que resulta aplicable el Estatuto y en los que concurre el Código del Trabajo, no siendo lícito para el intérprete aplicar la normativa en sentido distinto, debiendo ajustarse la Administración al principio de legalidad; y por último, el argumento que consideramos más controversial es el relativo al ámbito de aplicación del Código del Trabajo, establecido en su artículo $1^{\circ}$, que previene que sus normas no se aplicarán a los funcionarios de la Administración del Estado siempre que se encuentren sometidos por ley a un estatuto especial, circunstancia entendida por este sector de la jurisprudencia como elemento excluyente debido a que el inciso final del artículo $4^{\circ}$ de la Ley $\mathrm{n}^{\mathrm{o}}$ 18.883, establece remisión expresa al contrato y, consiguientemente, a la aplicación del Código Civil. ${ }^{29}$

A modo de ejemplo, se ha señalado: "lo anterior en razón de lo establecido, a su vez en el inciso tercero del artículo $1^{\circ}$ del mencionado Código, que previene que sus normas se aplicarán supletoriamente a los funcionarios de la administración centralizada y descentralizada del Estado, del Congreso Nacional y del Poder Judicial, en los aspectos o materias no reguladas en los respectivos estatutos a que ellos están sujetos, siempre que no fueren contrarios a la normativa (...) Que en la especie no se trata de hacer efectivas de modo subsidiario ciertas reglas del Código Laboral a los funcionarios de un servicio público, en defecto de las disposiciones estatutarias a las que ellos estén sometidos, sino de encuadrar la situación de la actora a toda la normativa que contiene dicho Código, en circunstancias que sus servicios se ejecutaron de una modalidad prevista y autorizada por la ley que rige a este organismo" (Espinoza Cerda, Alejandra con Municipalidad de Maipu, 2006, Considerando $5^{\circ}$ y $6^{\circ}$ ).

Sin embargo, no concordamos con esta posición porque la Administración al no apegarse a la hipótesis del artículo 4 de la Ley $\mathrm{N}^{\mathrm{o}}$ 18.883, materializa la infracción al principio de legalidad (Soto, 1996: 150), lo que ocurriría en aquellos casos de contratación permanente $\mathrm{o}$ en los que existe subordinación o dependencia. Lamentablemente, la interpretación que se inclina por la aplicación del Código Civil, aun en circunstancias en que son verificables indicios de subordinación o dependencia como en las obligaciones de asistencia, cumplimiento de horarios o deber de sujetarse a instrucciones ${ }^{30}$ o, incluso, reconociendo explícitamente la existencia de subordinación o dependencia ${ }^{31}$, ha mantenido

\footnotetext{
${ }^{28}$ Pradines Pradines, Claudia y Otros con Municipalidad de San Juan De La Costa (2015)

${ }^{29}$ Respecto a estos argumentos. Cfr. Espinoza Cerda Alejandra con Municipalidad de Maipú (2006); Avila Aguilera Mario con Lavín Infante Joaquín (2006); Tapia Riquelme Alicia Marcela con Municipalidad de Santiago (2009); Sepúlveda González Elizabeth con I. Municipalidad de Concepción (2006).

${ }^{30}$ Espinoza Cerda Alejandra con Municipalidad de Maipú (2006), Considerando $10^{\circ}$

${ }^{31}$ Sepúlveda González Elizabeth con Municipalidad de Concepción, Considerando $15^{\circ}$.
} 
dicha posición la que, según nuestro análisis, contradice de forma clara los supuestos de la contratación a honorarios y deja a los trabajadores desprovistos de tutela jurídica.

Ahora bien, como manifestamos en un inicio, hemos asistido a un nuevo periodo en que la Cuarta Sala de la Corte Suprema se ha inclinado por la aplicación del Código del Trabajo $^{32}$, a través de diversos argumentos que se han centrado principalmente en la supletoriedad de la normativa laboral por razones de texto y el reconocimiento de la importancia principio de primacía de la realidad, tanto en su rol informativo como interpretativo (Palomo, 2007: 60).

En cuanto a las razones de texto, la Corte Suprema ha seguido una línea interpretativa (Palavecino, 2000) (Yáñez, 2010) coherente con lo manifestado por el Profesor Claudio Palavecino y Eduardo Yáñez, quienes abordaron el conflicto interpretativo para la correcta solución del problema de los trabajadores a honorarios. Asimismo, respecto a la idea de excluir la aplicación del Código del Trabajo y, particularmente, en lo relativo a la remisión del artículo $1^{\circ}$ inciso final, se manifestó acertadamente:

"Pero resulta que, como vimos, dicha excepción excluye a los trabajadores o funcionarios sometidos por ley a un estatuto especial. El fallo no señala en parte alguna cuál es este estatuto legal especial aplicable a los trabajadores a honorarios de la Administración. Pregunta válida si se tiene en cuenta que el propio Estatuto Administrativo los excluye de su ámbito de aplicación. ¿Habrán entendido los sentenciadores que dicho "Estatuto especial” es, precisamente, su contrato a honorarios, al cual remite el artículo 10 inciso final del Estatuto Administrativo? Como lo dijimos en un comienzo, el Código del Trabajo alude a un régimen legal, no contractual.”(Palavecino, 2000: 75)

La Corte Suprema, en el primer fallo que unifica la jurisprudencia en este sentido, ha señalado que la "(...) disyuntiva se orienta hacia la aplicación del Código del Trabajo o del Código Civil, conclusión que deriva de que en el caso se invoca el artículo $4^{\circ}$ de la Ley $\mathrm{N}^{\circ} 18.883$, norma que, sustrayéndose del marco jurídico estatuario que establece para los funcionarios que regula, permite contratar sobre la base de honorarios en las condiciones que allí se describen y que se consignaron en el fundamento quinto, las que, en general, se asimilan al arrendamiento de servicios personales regulados en el Código Civil y que, ausentes, excluyen de su ámbito las vinculaciones pertinentes, correspondiente subsumirlas en la normativa del Código del Trabajo, en el evento que se presenten los rasgos características de este tipo de relaciones (...)"(Vial con Municipalidad de Santiago, 2014, Considerando $2^{\circ}$ )

De forma adicional, los recientes fallos de unificación de jurisprudencia que siguen esta línea interpretativa han dado muestra de la importancia de la aplicación del principio de primacía de la realidad, refiriendo el máximo tribunal que, en estos casos, no basta considerar únicamente los términos de los respectivos documentos conforme a los que el trabajador se incorporó a la dotación municipal, como los acuerdos a que hayan arribado las

\footnotetext{
32 Véase Vial Paillán, Juan con Municipalidad de Santiago (2015); Guzmán Tapia Jorge con Servicio de Vivienda y Urbanismo (2015); Medina Jorquera, Margarita con Municipalidad De San Antonio (2015); Ríos Salazar, Boris con Servicio de Vivienda y Urbanismo (2016); González Vera, Verónica y Otros con Municipalidad de Talca (2016).
} 
partes, sino se debe estar a lo que sucede en la práctica, en virtud del artículo 8 inciso primero del Código del Trabajo, que consagra el principio de primacía de la realidad y que haría presumir la existencia de un contrato de trabajo, cuya expresión se daría al intentar encubrir a un trabajador dependiente bajo la apariencia de ser uno independiente, lo que a juicio de la Corte Suprema, obliga necesariamente a determinar la verdadera naturaleza de la prestación. ${ }^{33}$

Sin perjuicio de estas posiciones acogidas por el máximo tribunal, un recurso reciente de unificación de jurisprudencia se ha alejado de la interpretación que estimábamos ajustada a derecho, sustentándose nuevamente en una hermenéutica que a nuestro parecer es más bien formalista y no considera otros elementos de análisis. En este sentido, el fallo aduce que:

"Útil también se hace considerar que el principio de legalidad de la acción del Estado que enuncian los artículos $6^{\circ}$ y $7^{\circ}$ de la Constitución Política de la República, según el cual los órganos estatales no tienen más atribuciones que las conferidas expresamente por las leyes y que recoge, asimismo, el artículo $2^{\circ}$ de la Ley Orgánica Constitucional sobre Bases Generales de la Administración del Estado, impide a los Municipios contratar personal sujeto al Código del Trabajo fuera de los casos específicamente señalados por la ley, como ocurre en las situaciones a que alude el artículo $3^{\circ}$ del Estatuto Administrativo de los Funcionarios Municipales contenido en la citada Ley $\mathrm{N}^{\circ} 18.883$; de los empleados de los servicios traspasados a las Municipalidades de acuerdo con el Decreto Ley $\mathrm{N}^{\circ} 3.063$, de 1978, y de los médicos cirujanos que se desempeñan en los gabinetes psicotécnicos municipales." (Pradines Pradines, Claudia y otros con Municipalidad de San Juan de la Costa, 2015, Considerando $8^{\circ}$ )

Estimamos que en este caso se omite una interpretación acorde al Orden Público Laboral, el que resulta gravitante al momento de resolver esta controversia y robustece aún más la posición adoptada en este último tiempo por la Corte Suprema, puesto que implica la observancia a la normativa constitucional en su total dimensión.

\section{EL CONFLICTO DESDE LA ÓPTICA DEL ORDEN PÚBLICO LABORAL.}

Compartiendo la posición de que el conflicto jurídico debe ser abordado a través de la aplicación del Código del Trabajo, existen argumentos asociados al Orden Público Laboral y a la comprensión del Derecho Laboral como disciplina jurídica, que refuerzan las consideraciones aportadas por la Corte Suprema y la doctrina nacional.

En este sentido, el Derecho del Trabajo como rama tiene una serie de características propias, entre las que podemos mencionar el hecho de tratarse de una disciplina autónoma, dinámica, de gran fuerza expansiva, etcétera., sin embargo, una de sus principales características es ser un Derecho de Orden Público.

El Orden Público ha sido definido como "el conjunto de reglas esenciales para el mantenimiento de la sociedad" (Ducci, 1984: 55), circunstancia que nos parece indiscutida en el caso del Derecho Laboral, al considerar su función pacificadora y carácter

\footnotetext{
${ }^{33}$ Medina Jorquera, Margarita con Municipalidad de San Antonio (2015), Considerando $7^{\mathbf{0}}$.
} 
transaccional (Gamonal, 2012: 12). A este respecto, una manifestación de ello se observa en los procesos de movilización de los trabajadores a honorarios, los que podemos atribuir a priori a la necesidad tutela jurídica y, consecuencialmente, traen aparejados la amenaza de la estabilidad de las relaciones laborales. Por lo tanto, este tipo de circunstancias nos permiten manifestar que, las normas del Derecho del Trabajo al momento de proteger, van a generar además la pacificación del conflicto, lo que dará estabilidad a la sociedad y justificará la calidad de Derecho de Orden Público de la normativa laboral.

Ahora bien, el Orden Público Laboral al formar parte del Orden Público General, comparte la búsqueda del bien común de la sociedad, no obstante ello, el primero reviste la particularidad de ser de carácter unilateral o unidireccional (Tapia, 2005: 212), que se explica por el objetivo tutelar del Derecho del Trabajo. En este sentido, el Orden Público Laboral se caracteriza en la idea de un sistema de derechos imperativos mínimos, fijados previamente por el legislador como materia irrenunciable y que, por lo tanto, su modificación o vulneración ha sido vedada tanto para el trabajador como para el empleador. En el caso del primero, el vínculo de subordinación trae consigo la ausencia de poder negociador e implica la necesidad de garantizar estándares básicos de contratación; en el caso del segundo, se establece un piso básico que limita la libre contratación pero sólo en sentido prohibitivo, es decir, el empleador no podrá contratar bajo el mínimo legal pero estará facultado para acordar con el trabajador mejores condiciones de contratación.

Por tanto, entre los rasgos que caracteriza Orden Público Laboral, encontramos que este se ha erigido esencialmente sobre la base de mínimos de protección que resguardan a la parte considerada débil en un vínculo jurídico de subordinación y dependencia, siendo esta razón la que permite explicar que por el carácter unidireccional se permita la reforma laboral in melius.

Adicionalmente, el Orden Público Laboral al materializarse en principios fundamentales reconocidos en la Constitución, tendrá como característica adicional su carácter expansivo, el que es otorgado por la naturaleza jurídica de estos derechos (Ugarte, 2011). Así las cosas, debemos destacar que este elemento justifica, particularmente, la decisión del legislador de otorgar al Código del Trabajo la mayor cobertura posible, lo que se demuestra en el establecimiento de la supletoriedad del estatuto laboral y de la presunción de la relación laboral, consagrados en sus artículos 1 y 8 del Código del Trabajo, respectivamente.

A este respecto, la Historia de la Ley 18.620: Código del Trabajo, evidencia el fundamento y alcance del artículo $1^{\circ}$ de la normativa, señalando los legisladores que "el sentido de la enmienda es el de enfatizar la generalidad del campo de aplicación del Código del Trabajo, manteniendo su carácter expansivo, en cuanto su normativa se aplicará también supletoriamente a los funcionarios públicos o trabajadores de empresas afectas al sector público" (Congreso Nacional de Chile, 1987, p.519).

Los elementos expuestos relativos al Orden Público Laboral resultan trascendentales para analizar el conflicto de los trabajadores a honorarios en consideración de su carácter unidireccional y expansivo y su consagración en la Constitución Política de la República, la que a través del reconocimiento de derechos fundamentales laborales específicos, permite 
realizar una lectura crítica de la interpretación que reconoce la naturaleza civil de este vínculo, no sólo desde la perspectiva legal sino desde la perspectiva Constitucional.

La Constitución reconoce derechos fundamentales laborales específicos en el artículo $19 \mathrm{~N}^{\circ} 16, \mathrm{~N}^{\circ} 17, \mathrm{~N}^{\circ} 18$ y $\mathrm{N}^{\circ} 19$, sin embargo, para efectos de análisis de la problemática nos centraremos principalmente en lo consagrado en el numeral 16, en lo relativo a la libertad de trabajo y el derecho a su protección, en el derecho a la libre contratación y elección del trabajo, y en la proscripción de toda forma de discriminación que se encuentre fuera de los supuestos establecidos en la norma.

"Artículo $19 n^{\circ}$ 16.- La libertad de trabajo y su protección.

Toda persona tiene derecho a la libre contratación y a la libre elección del trabajo con una justa retribución.

Se prohíbe cualquiera discriminación que no se base en la capacidad o idoneidad personal, sin perjuicio de que la ley pueda exigir la nacionalidad chilena o límites de edad para determinados casos.

Ninguna clase de trabajo puede ser prohibida, salvo que se oponga a la moral, a la seguridad o a la salubridad públicas, o que lo exija el interés nacional y una ley lo declare así."

Lo primero que debemos determinar es qué está protegiendo el artículo $19 \mathrm{~N}^{\circ} 16$. En este sentido, en el encabezado del artículo el constituyente ha reconocido el derecho a la libertad de trabajo y a la protección del mismo, consagrándose sus dimensiones específicas a través del reconocimiento de la libertad de contratación y de elección del trabajo con justa retribución, reconocimiento que se ha otorgado en forma amplia según se desprende del vocablo "toda persona", y la dimensión relativa a la proscripción a cualquier discriminación fuera de las hipótesis que el constituyente refiere.

Comprendemos que en el caso de la libertad de contratación y elección del trabajo existiría una doble vertiente; por un lado, el empleador goza de la libertad para contratar a un determinado trabajador sin que se le pueda imponer alguno y, por otro, el trabajador puede optar por qué trabajo quiere desempeñar y la forma de realizarlo, ya sea de forma independiente o dependiente, en este último caso, no se encuentra constreñido a elegir un empleador determinado.

Ahora bien, la idea matriz de libertad de trabajo y su protección permite comprender el alcance de este derecho. En este sentido, según se desprende de las actas de la Comisión de Estudio de la Nueva Constitución (Comisión Ortúzar), la protección del trabajo tiene un sustrato profundo, debiendo destacarse lo manifestado por el Sr. Enrique Evans, integrante de la Comisión, al momento de discutirse estos elementos, quien aclaró que la frase "libertad de trabajo y su protección" refería más a la idea de protección del trabajo y no de la libertad, puesto que esta última o las libertades en general, se bastan a sí mismas y no tendría sentido sostener que se busca proteger a estas por medio de la consagración del texto constitucional. Esta alocución fue posterior a lo manifestado por el Sr. Sergio Diez, al señalar que el país ya no tenía necesidad de afirmar conceptos como dignidad en el trabajo, 
dando a entender que, en el contexto de la discusión de la Comisión, este valor se encontraría intrínsecamente ligado a la noción del trabajo. ${ }^{34}$

A lo anteriormente expuesto, es necesario añadir lo manifestado por el Profesor Alejando Silva Bascuñán, miembro de la Comisión de Estudio de la Nueva Constitución, el que en relación a la libertad de trabajo ha referido que "corresponde en primer lugar a la Constitución Política, como expresión de la máxima jerarquía normativa y garante de los derechos individuales y colectivos, asegurar ampliamente la libertad de trabajo y velar porque se establezcan las condiciones sociales necesarias para que pueda desarrollarse dignamente". (Silva, 2010: 222)

Asimismo, la protección de la libertad de trabajo no apunta solamente a sus manifestaciones particulares de la libertad de contratación y la libertad de elección; por el contrario, estos elementos están dotados de cierto contenido relativo a la noción del trabajo digno, circunstancia que tiene implicancias en nuestro objeto de estudio, puesto que por mandato constitucional no basta garantizar la libre elección del trabajo, sino que es necesario que el mismo sea digno, valor que se ha homologado a la noción de trabajo decente, referido anteriormente en este trabajo.

En el caso de los trabajadores a honorarios, particularmente, las condiciones de contratación ameritan su protección desde la óptica del derecho laboral, entendiendo que este se erige como garantía de derechos mínimos que salvaguardan la dignidad del trabajo. Por lo tanto, asumir la naturaleza civil del vinculo por sobre consideraciones fácticas, implica alejarnos de la noción de trabajo digno y habilitar a la Administración para que realice prácticas proscritas en nuestro actual Estado de Derecho, concordando en este aspecto con lo manifestado por la Corte Suprema: “...no sólo porque la vigencia del Código del Trabajo constituye la regla general en el campo de las relaciones personales, sino porque no es dable admitir la informalidad laboral y suponer que por tratarse de un órgano del Estado, que debe someterse al principio de la juridicidad, recogido en los artículos 6 y 7 de la Constitución Política de la República, puede invocar esa legalidad para propiciar dicha precariedad e informalidad laboral, que por lo demás se encuentra proscrita en un Estado de Derecho." (Vial con Municipalidad de Santiago, 2014, Considerando $9^{\circ}$ ).

En este sentido, la precariedad laboral se produce por las condiciones anómalas de contratación de los trabajadores a honorarios y, en términos reactivos, en caso de una negativa en la aplicación del Código del Trabajo, implicaría que no exista corrección en la vulneración del ordenamiento jurídico, no solo del Código del Trabajo y el Estatuto Administrativo, sea de funcionarios del gobierno central o municipal, sino que atentaría al propio Estado de Derecho cristalizado en la Carta Fundamental, según las consideraciones expuestas.

Adicionalmente, indistinto de la noción de trabajo digno, nos parece pertinente analizar un segundo aspecto del Orden Público Laboral consagrado en el artículo $19 \mathrm{~N}^{\circ} 16$, relativo a la prohibición de cualquier discriminación que no se base en la capacidad o idoneidad personal.

\footnotetext{
${ }^{34}$ COMISIÓN CONSTITUYENTE (1976) p.535.
} 
A priori, en este aspecto nos parece al menos dudosa o cuestionable la situación en que se encuentran los trabajadores a honorarios. En un primer aspecto, existen problemas en el hecho de que personas realicen un trabajo similar y reciban un tratamiento normativo o un reconocimiento de derechos distinto, circunstancia que ocurriría con los trabajadores a honorarios que desarrollan labores semejantes a los funcionarios ${ }^{35}$. Sin embargo, en este caso, la normativa relativa al empleo público es una limitante para garantizar idénticos derechos, entendiendo que con la normativa recientemente promulgada será de competencia privativa de los alcaldes realizar acciones que finalmente tiendan a resguardar la igualdad de derechos en favor de los trabajadores a honorarios y, en este escenario, no resultaría jurídicamente procedente reconocerles prerrogativas propias de los funcionarios municipales o públicos, sin perjuicio de las responsabilidades que puedan recaer sobre la autoridad.

Ahora bien, totalmente distinto es sostener que los trabajadores a honorarios que prestan servicios bajo régimen de subordinación o dependencia y reciben una contraprestación en dinero a cambio de una determinada labor, deban ser excluidos de la aplicación del Código del Trabajo. Estimamos que, en consideración del ámbito de cobertura establecido en el artículo $1^{\circ}$ de la normativa laboral, dicha situación implicaría un atentado contra la prohibición de discriminación en el trabajo, debido a que no existe una razón fundada en capacidad o idoneidad personal, que justifique obviar la hipótesis establecida en el artículo $8^{\circ}$ del Código del Trabajo.

Esta visión adquiere mayor fuerza si tenemos presente el mandato establecido en el artículo $19 \mathrm{~N}^{\circ} 26$ de la Constitución, el que otorga una garantía para los ciudadanos frente al legislador, quien no puede restringir ni limitar en su esencia los derechos fundamentales reconocidos por la Constitución. Así las cosas, peligroso es sostener que el legislador, al momento de determinar el ámbito de aplicación del Código del Trabajo y regular el Estatuto Administrativo, haya buscado consagrar la exclusión de los trabajadores a honorarios frente a esta problemática, cuando esta circunstancia materializaría, en sí misma, una discriminación arbitraria en relación a lo que ocurre con un trabajador del ámbito privado que al concurrir los elementos de la relación laboral le es reconocida la necesidad de tutela, existiendo en este caso solo como diferencia el hecho de que el Estado no es su empleador.

La particularidad de que el Estado sea empleador y la circunstancia de no cumplirse con los presupuestos de contratación a honorarios al existir subordinación o dependencia, no puede traducirse en ausencia de la aplicación de normativa tutelar, considerando que esta situación socavaría incluso las bases de la propia institucionalidad, entendiendo que la finalidad del Estado es promover el bien común, contribuyendo a la creación de condiciones sociales que permitan a todos la mayor realización espiritual y material posible, con apego estricto a los derechos y garantías que la Constitución establece. En este sentido, la falta de apego al principio de legalidad - al existir una contratación de honorarios anómala - no trae aparejado el desconocimiento del Orden Público Laboral, el

\footnotetext{
${ }^{35}$ Cuestionable conforme a lo dispuesto en el artículo $7^{\circ}$ del Pacto de Derechos Económicos, Sociales y Culturales, normativa vigente y ratificada por nuestro País.
} 
que resulta plenamente exigible y se materializa en la observancia a los derechos laborales fundamentales específicos reflejados, entre otras normativas, en el establecimiento de derechos mínimos legales en el Código del Trabajo, que es la normativa general en el caso de los trabajadores dependientes.

"El trabajo no constituye únicamente un esfuerzo mecánicamente ordenado a un fin, sino que es un acto personal, una obra de inteligencia, de voluntad, de la libertad, de la conciencia, es decir, un hecho que se eleva al orden ético. Es por ello y por la necesidad de garantizar la dignidad de esta expresión del hombre, que resulta indispensable que el ordenamiento jurídico regule y proteja el ejercicio de la actividad laboral". (Silva, 2010: 222)

Por lo tanto, estimamos que se ha producido una errónea diferenciación en la aplicación del Código del Trabajo por la calidad de empleador del Estado y, en base a esto, se ha buscado reconducir el conflicto únicamente la normativa que el propio Estado se ha dado para la contratación de su personal ${ }^{36}$, vulnerando con ello la igualdad ante la ley. En este sentido, concurriendo los elementos esenciales de la relación laboral en la contratación a honorarios, debemos ser enfáticos en señalar que no existen impedimentos de orden legal para la aplicación del Código del Trabajo, básicamente porque estos trabajadores no están bajo el supuesto del artículo $4^{\circ}$ de la Ley $\mathrm{N}^{\circ} 18.883$ o del artículo $11^{\circ}$ de la Ley $\mathrm{N}^{\circ} 18.834 \mathrm{u}$ otra normativa que justifique esta contratación y que permita excusar al Estado de la necesidad de tutela que constitucionalmente tienen estos trabajadores, justificada en la noción de trabajo digno y de la no discriminación laboral, que es la concreción del principio general de igualdad ante la ley en el ámbito del Derecho del Trabajo (Silva, 2010: 250).

Finalmente, es preciso recalcar que en virtud del artículo 5 inciso $2^{\circ}$ de la Constitución, es deber de los órganos de la Administración respetar y promover los derechos esenciales que emanan de la naturaleza humana, los que han sido garantizados en la Constitución y en Tratados internacionales ratificados por Chile y que se encuentren vigentes, debiendo considerarse para efectos de esta problemática los artículos $7^{\circ}$ y $8^{\circ}$, del Pacto Internacional de Derechos Económicos, Sociales y Culturales y el Convenio № 111 de la Organización Internacional del Trabajo, sobre la discriminación, del año 1958, especialmente lo consagrado en su artículo $2^{\circ}$ : "Todo miembro para el cual este Convenio se halle en vigor se obliga a formular y llevar a cabo una política nacional que promueva, por métodos adecuados a las condiciones y a la práctica nacionales, la igualdad de oportunidades y de trato en materia de empleo y ocupación, con objeto de eliminar cualquier discriminación a este respecto".

\section{CONCLUSIONES.}

De lo expuesto en el presente trabajo podemos señalar que la contratación a honorarios al interior de las municipalidades, es un fenómeno generalizado en el funcionamiento de la Administración local, representando la mayoría de la masa laboral del sector. Adicionalmente, esta situación podría eventualmente variar a través de la normativa

\footnotetext{
${ }^{36}$ Pradines Pradines, Claudia y Otros con Municipalidad de San Juan de la Costa (2015) Considerando $7^{\circ}$.
} 
recientemente promulgada por la Presidenta Michelle Bachelet, relativa al proyecto de ley que modifica disposiciones aplicables a los funcionarios municipales y entrega nuevas competencias a la Subsecretaría de Desarrollo Regional y Administrativo, otorgando la facultad de fijar y modificar las plantas municipales a los alcaldes.

Sin embargo, debemos advertir que esta normativa está destinada principalmente a los funcionarios a contrata y, marginalmente, a los trabajadores a honorarios a Suma Alzada, a quienes se les establece la posibilidad de pasar a la contrata y que abarcan solamente al $18 \%$ de los honorarios municipales. En este sentido la contratación vía programas comunitarios representa el $79,23 \%$ de los honorarios municipales y el $44,43 \%$ del total del personal municipal a nivel nacional.

Adicionalmente, en virtud de las cifras entregadas por el gobierno en relación a los beneficiarios de la normativa pronta entrar en vigencia, estimamos que es probable que la problemática de los trabajadores a honorarios se mantenga incólume y, en dicho caso, al menos de forma reactiva nuestros tribunales de justicia debiesen otorgar tutela jurídica tanto por razones de texto, en virtud del artículo $1^{\circ}$ del Código del Trabajo, en relación con su artículo $8^{\circ}$, como por la debida observancia del Orden Público Laboral, particularmente en lo relativo al artículo $19 \mathrm{n}^{\circ} 16$, que consagra la libertad de trabajo y su protección, la que hemos caracterizado en la noción de trabajo digno y ajeno de formas arbitrarias de discriminación.

Por último, estimamos que esta decisión en torno a la protección por la vía del Código del Trabajo pasa por criterios y consideraciones jurídicas, que son reactivas y debiesen ser transitorias en tanto se inicien procesos legislativos que establezcan una política pública que solucione la raíz de este conflicto, permitiendo que en nuestro país no existan trabajadores de primera o segunda categoría, pudiendo gozar todos en igual medida de los derechos laborales mínimos reconocidos en nuestra Constitución y en los tratados internacionales, los que obligan a nuestro país a garantizar, entre otros derechos, la seguridad social, la libertad sindical, y la igualdad ante la ley, a través de la prohibición de tratos discriminatorios en materia de empleo, consagrándose de esta forma un sistema de relaciones laborales en el sector público, que resulte acorde a las nociones de trabajo decente.

\section{BIBLIOGRAFÍA.}

BACHELET JERÍA, Michelle (2015). Mensaje Presidencial / 21 de mayo de 2015. Disponible en: <http://21demayo.gob.cl/2015/>

BACHELET JERIA, Michelle (2015). Proyecto de Ley que modifica disposiciones aplicables a los funcionarios municipales y entrega nuevas competencias a la Subsecretaría de Desarrollo Regional y Administrativo. Disponible en: $<$ https://www.camara.cl/pley/pley_detalle.aspx?prmID=10479\&prmBoletin=10057-06>

CAAMAÑO ROJO, Eduardo (2008). El reconocimiento de la libertad sindical y el problema de la representación de los trabajadores en la negociación colectiva. Revista de Derecho de la Pontificia Universidad Católica de Valparaíso XXX. 
CAMARA DE DIPUTADOS DE CHILE (2014). Proyecto de acuerdo $n^{o}$ 256: Solicitar $a$ S.E. la Presidenta de la República, el envío de un proyecto de ley que modifique el artículo 11 de la Ley $N^{o} 18.834$ y el artículo $4^{\circ}$ de la Ley $N^{\circ} 18.883$, con el objeto que los funcionarios a honorarios de la Administración del Estado accedan a los beneficios de la Ley $N^{o}$ 20.255. Periodo legislativo 2014-2018, Sesión 104. (Valparaíso, Biblioteca del Congreso Nacional)

CENTRAL UNITARIA DE TRABAJADORES (2014). Funcionarios formaron Unión Nacional de Trabajadores Públicos a Honorarios de Chile. Disponible en: $<$ http://www.cut.cl/Portal/index.php?option=com_content $\& v i e w=\operatorname{article} \& i d=2610: 2014$ -12-03-13-59-06\&catid=293: nacionales-cut\&Itemid=542>

COMISIÓN CONSTITUYENTE. (1976). Actas Oficiales de la Comisión Constituyente, Tomo VI. Disponible en: <http://www.bcn.cl/lc/cpolitica/actas_oficiales-r>

CONGRESO NACIONAL DE CHILE (1993). Historia de la Ley No 19.280: Modifica Ley $\mathrm{N}^{\circ}$ 18.695, Orgánica Constitucional de Municipalidades, y establece normas sobre plantas de personal de las Municipalidades. (Valparaíso - Biblioteca del Congreso Nacional).

CONGRESO NACIONAL DE CHILE (1987). Historia de la Ley No 18.620: Código del Trabajo. (Valparaíso - Biblioteca del Congreso Nacional)

DIRECCIÓN DE PRESUPUESTOS (2015). Protocolo de Acuerdo firmado entre el Gobierno de Chile y la Agrupación Nacional de Empleados Fiscales (ANEF). Disponible en: <http://www.dipres.gob.cl/594/w3-article-133172.html>

GAMONAL CONTRERAS, Sergio (2012). Fundamentos del Derecho Laboral. (Santiago, Editorial Legal publishing)

GHAI, Draham (2003). Trabajo Decente. Conceptos e Indicadores. Revista Internacional del Trabajo $\mathrm{N}^{\circ} 122$, pp. 125-160.

HENRÍQUEZ, Helia y RIQUELME, Verónica (2006). Lejos del trabajo decente: El empleo desprotegido en Chile. Cuaderno de Investigación $\mathrm{N}^{\mathrm{o}}$ 30. (Santiago, Departamento de Estudios Dirección del Trabajo)

MUÑOZ VALDENEGRO, Catalina y UMAÑA TORRES, Thomas (2012). El contrato de Prestación de Servicios Civiles como Mecanismo de Elusión de los Efectos de una Relación Laboral: Criterios Judiciales y Administrativos Diferenciadores. Memoria para Optar al Grado de Licenciado en Ciencias Jurídicas y Sociales. (Santiago, Facultad de Derecho, Universidad de Chile)

PALAVECINO CACERES, Claudio (2000). La contratación a Honorarios en la Administración Pública: El Estado como fuente de Empleo Precario. Revista Laboral Chilena $\mathrm{n}^{\mathrm{o}} 88$ (7), pp. $75-81$.

PALOMO VÉLEZ, Rodrigo (2007). El rol de los principios del Derecho del Trabajo. Antecedentes conceptuales sobre el estado del arte en Chile. Revista Laboral Chilena $\mathrm{N}^{\mathrm{o}}$ 161 (11), pp. $59-69$.

RADIO BIOBIO (2015). Funcionarios a honorarios exigen contrataciones 'dignas' y mejoras laborales. Disponible en: <http://www.biobiochile.cl/2015/10/10/funcionariosa-honorarios-exigen-contrataciones-dignas-y-mejoras-laborales.shtml> 
RADIO BIOBIO (2016). Trabajadores a honorarios del Minvu en paro nacional: acusan incumplimiento del Gobierno. Disponible en: $<$ http://www.biobiochile.cl/2016/04/22/trabajadores-a-honorarios-del-minvu-en-paronacional-acusan-incumplimiento-del-gobierno.shtml>

REAL ACADEMIA ESPAÑOLA (2001). Diccionario de la Lengua Española. Tomo II 22a Edición. (España, Espasa Calpe S.A.)

REVISTA BAGUAL (2014). Declaración Unión de Trabajadores Municipales a Honorarios de Chile. Disponible en: <http://www.revistabagual.cl/2014/08/declaracionunion-de-trabajadores.html>

SILVA BASCUÑAN, Alejandro. (2010). Tratado de derecho constitucional. de los derechos y deberes constitucionales. Tomo XIII. (Santiago, Editorial Jurídica de Chile.)

SINDICATO INDEPENDIENTE DE TRABAJADORES HONORARIOS DE LA ILUSTRE MUNICIPALIDAD DE MAIPÚ. (2011). Presentación ante la Comisión del Trabajo y La seguridad Social de la H. Cámara de Diputados de Chile. Disponible en < http://www.honorariosmaipu.cl/documentos/presentacion-en-congreso-nacional.pdf >

SOTO KLOSS, Eduardo (1996). Derecho Administrativo: Bases fundamentales. Principio de Juridicidad. Tomo II. (Santiago, Editorial Jurídica de Chile).

SOTO KLOSS, Eduardo (2012). Derecho Administrativo: Temas fundamentales. $3^{\circ}$ Edición. (Santiago, Editorial Abeledo Perrot / Legal Publishing)

SUBSECRETARÍA DEL DESARROLLO REGIONAL Y ADMINISTRATIVO (2016). Congreso despacha proyecto que modifica y descentraliza plantas municipales y que beneficia a 33 mil funcionarios. Disponible en: < http://www.subdere.gov.cl/sala-deprensa/congreso-despacha-proyecto-que-modifica-y-descentraliza-plantas-municipalesy-que-ben>

TAPIA GUERRERO, Francisco (2005). Subordinación o dependencia en el Contrato del Trabajo, en el proceso de transformación de la empresa. (Santiago, Editorial Lexis Nexis).

UGARTE CATALDO, José Luis. (2011). Los Derechos en su nueva hora: La Teoría externa de los derechos fundamentales. Revista de Derecho Universidad Católica del Norte, $\mathrm{N}^{\mathrm{o}} 2$ - Año 18, pp. 361-373.

VERGARA ALEJANDRO, en MERCURIO LEGAL (2016) Contratos a honorarios para servicios personales habituales y dependientes en la Administración pública: su naturaleza laboral. El Código del Trabajo como estatuto común y supletorio. Disponible en:

$<\mathrm{http}$ ///www.elmercurio.com/Legal/Noticias/AnalisisJuridico/2016/05/02/Contratos-a-honorarios-para-servicios-personales-habituales-ydependientes-en-la-Administracion-publica-su-naturaleza-laboral.aspx $>$

WALKER ERRÁZURIZ, Francisco (1960) Introducción al Estudio del Derecho del Trabajo. (Santiago, Editorial Jurídica de Chile)

YAÑEZ MONJE., Eduardo (2010). Contratos a Honorarios en la Administración Pública: Comentario de una Sentencia de la Corte Suprema. Revista de Actualidad Laboral, $\mathrm{N}^{\circ}$ LXXXVI, pp. 64-67. 


\section{NORMAS CITADAS}

D.F.L. No 1, 31 de julio de 2002, Fija Texto Refundido y Sistematizado del Código del Trabajo.

Decreto $\mathrm{N}^{\mathrm{o}}$ 100, 17 de septiembre de 2005, Fija el Texto Refundido, Coordinado y Sistematizado de la Constitución Política de la Republica de Chile.

Ley $\mathrm{N}^{\mathrm{o}}$ 18.883, 29 de diciembre de 1989, Aprueba Estatuto Administrativo para Funcionarios Municipales.

Ley No 18.834, 23 de septiembre de 1989, Aprueba Estatuto Administrativo.

D.F.L N ${ }^{\circ}$ 1, 26 de julio de 2006, Fija el Texto Refundido, Coordinado y Sistematizado de la Ley $\mathrm{N}^{\circ}$ 18.695, Orgánica Constitucional de Municipalidades.

Decreto $\mathrm{N}^{\mathrm{o}}$ 326, 27 de mayo 1989, Promulga el Pacto Internacional de Derechos Económicos, Sociales y Culturales, Adoptado por la Asamblea General de la Organización de las Naciones Unidas el 19 de diciembre de 1966, suscrito por Chile el 16 de septiembre de 1969.

Decreto $\mathrm{N}^{\mathrm{o}} 733,13$ de noviembre de 1971, Aprueba Convenio $\mathrm{N}^{\circ} 111$, relativo a la Discriminación en Materia de Empleo y Ocupación, adoptado en la 42a Reunión de la OIT, en Ginebra, el 25 de Junio de 1958.

D.F.L N ${ }^{o}$ 1, 30 de mayo de 2000, Fija Texto Refundido, Coordinado y Sistematizado del Código Civil; de la Ley Número 4.808, sobre Registro Civil; de la Ley No 17.344, que Autoriza Cambio de Nombres y Apellidos; de la Ley No 16.618, Ley de Menores; de la Ley $N^{o} 14.908$, sobre Abandono de Familia y Pago de Pensiones Alimenticias, y de la Ley $\mathrm{N}^{\mathrm{o}}$ 16.271, de Impuesto a las Herencias, Asignaciones y Donaciones.

Ley $\mathrm{N}^{\circ}$ 19.280, 16 de diciembre de 1993, Modifica Ley No 18.695, Orgánica Constitucional de Municipalidades, y Establece Normas sobre Plantas de Personal de las Municipalidades.

Circular N ${ }^{o}$ 15.700, de Contraloría General de la República, 16 de marzo de 2012, Imparte instrucciones en materia de Registro de Decretos Alcaldicios y deja sin efecto Oficios $\mathrm{N}^{\mathrm{o}} \mathrm{s} 32.148$, de 1997 y 10.751 , de 1998.

Resolución N ${ }^{\circ}$ 1.600, de Contraloría General de la República, 30 de octubre de 2008, que Fija Normas sobre Exención del Trámite de Toma de Razón.

Decreto $N^{\circ} 1.186,18$ de enero 2008, Modifica Clasificaciones Presupuestarias.

Decreto No 854, 2 de diciembre de 2008, Determina Clasificaciones Presupuestarias.

Decreto Ley $\mathrm{N}^{\circ}$ 1263, 28 de noviembre de 1975, Orgánica de Administración Financiera del Estado.

Decreto Ley No 1.608, 7 de diciembre 1976, Dicta Normas para Implantar la Segunda Etapa de la Carrera Funcionaria y Otras Disposiciones.

Decreto Ley No 249, 5 de enero de 1974, Fija Escala Única de Sueldos para el Personal que señala.

Decreto $N^{\circ}$ 98, 19 de marzo de 1991, Establece Modalidad a la que deben ajustarse la celebración de Convenios que involucren la Prestación de Servicios Personales.

Ley No 18.962, 10 de marzo de 1990, Ley Orgánica Constitucional de Enseñanza. 
Ley $\mathrm{N}^{\mathrm{o}} 20.237,24$ de diciembre de 2007, Modifica el Decreto Ley $\mathrm{N}^{\circ}$ 3.063, de 1979, sobre Rentas Municipales; la Ley No 18.695, Orgánica Constitucional de Municipalidades, y otros cuerpos legales, en relación con el Fondo Común Municipal y otras materias municipales.

Ley $\mathrm{N}^{\mathrm{o}} 19.602,25$ de marzo de 1999, Modifica la Ley No 18.695, Orgánica Constitucional de Municipalidades, en materia de Gestión Municipal.

Ley $\mathrm{N}^{\mathrm{o}}$ 19.296, 14 de marzo de 1994, Establece Normas sobre Asociaciones de Funcionarios de la Administración del Estado.

Ley No 20.255, 17 de marzo de 2008, Establece Reforma Previsional.

Decreto $\mathrm{N}^{\mathrm{o}}$ 187, 19 de agosto de 2011, Promulga el Convenio $\mathrm{N}^{\mathrm{o}} 187$ sobre Marco Promocional para la Seguridad y Salud en el Trabajo de la Organización Internacional del Trabajo.

\section{JURISPRUDENCIA JUDICIAL CITADA.}

Ávila Aguilera, Mario con Lavín Infante, Joaquín (2006): Corte Suprema, 12 de enero de 2006, Rol No 2.788-2004 (Casación en el Fondo).

Espinoza Cerda, Alejandra con Municipalidad de Maipú (2006): Corte Suprema, 18 de Octubre de 2006, Rol N 1.864-2005 (Casación en el Fondo).

González Vera, Verónica y Otros con Municipalidad de Talca (2016): Corte Suprema, 19 de abril de 2016, Rol No 5.699-2015 (Recurso de Unificación de Jurisprudencia).

Guzmán Tapia, Jorge con Servicio de Vivienda y Urbanismo (2015): Corte Suprema, 6 agosto 2015, Rol No 23.647-2014 (Recurso de Unificación de Jurisprudencia).

Medina Jorquera, Margarita con Municipalidad de San Antonio (2015): Corte Suprema, 9 de julio de 2015, Rol No 24.388-2014 (Recurso de Unificación de Jurisprudencia).

Pradines Pradines, Claudia y Otros con Municipalidad de San Juan De La Costa (2015): Corte Suprema, 5 de agosto de 2015, Rol No 24.904-2014 (Recurso de Unificación de Jurisprudencia).

Ríos Salazar, Boris con Servicio de Vivienda y Urbanismo (2016): Corte Suprema, 19 de abril de 2016, Rol Nº 8.002-2015 (Recurso de Unificación de Jurisprudencia).

Sepulveda González, Elizabeth con Municipalidad de Concepción (2006): Corte de Apelaciones de Concepción, 6 de enero de 2006, Rol 1.899-2005, Sentencia firme y ejecutoriada (Recurso de Apelación).

Tapia Riquelme, Alicia Marcela con Municipalidad De Santiago (2009): Corte Suprema, 29 de diciembre de 2009, Rol N 7.931-2009 (Casación en el Fondo).

Vial Paillán, Juan Con Municipalidad De Santiago (2015): Corte Suprema, 1 de abril de 2015, Rol No11.584-2014 (Recurso de Unificación de Jurisprudencia).

\section{JURISPRUDENCIA ADMINISTRATIVA CITADA}

DICTAMEN No 16.220, Contraloría General de la República, de 20 de mayo de 1982.

DICTAMEN No 40.021, Contraloría General de la República, de 2 de noviembre de 1998.

DICTAMEN No 44.597, Contraloría General de la República, de 18 de noviembre de 1999. 
DICTAMEN No 45.711, Contraloría General de la República, de 5 de diciembre de 2001. DICTAMEN N 20.045, Contraloría General de la República, de 16 de mayo de 2003. DICTAMEN N 29.501, Contraloría General de la República, de 14 de julio de 2003. DICTAMEN Nº 14.471, Contraloría General de la República, de 20 de marzo de 2004. DICTAMEN No 18.347, Contraloría General de la República, de 18 de abril de 2004. DICTAMEN N 7.023, Contraloría General de la República, de 10 de febrero de 2005. DICTAMEN N ${ }^{\circ}$ 7.266, Contraloría General de la República, de 10 de febrero de 2005. DICTAMEN No 25.694, Contraloría General de la República, de 30 de mayo de 2005. DICTAMEN No 57.217, Contraloría General de la República, de 6 de diciembre de 2005. DICTAMEN N ${ }^{\circ}$ 58.743, Contraloría General de la República, de 23 de octubre de 2009. DICTAMEN N ${ }^{\circ}$ 31.394, Contraloría General de la República, de 29 de mayo de 2012. DICTAMEN No 14.064, Contraloría General de la República, de 1 de marzo de 2013. ORDINARIO N 5299/0249, Dirección del Trabajo, de 14 de septiembre de 1992. 